\title{
Accommodation eWOM in the Sharing Economy: Automated Text Comparisons from a Large Sample.
}

\author{
Christine Pitt \\ Kirk Plangger \\ Theresa Eriksson
}

\begin{abstract}
Across many industries, individuals are increasingly relying on customer ratings and reviews on social media. While customer reviews often provide detailed diagnostic information about experiences, customer ratings often reduce the experience down to a simple number. Moreover, there is evidence to support that customer rating inflation is occurring on social media sites over time, especially in the sharing economy, and especially with regard to travel and tourism experiences. This paper conceptualizes how customer experiences are reduced into customer reviews and further abridged into customer ratings in both the traditional and sharing economy contexts. We propose that customers observe how service providers present themselves as a professional (established chain hotel) or amateur (owner operated vacation rental apartment), and then form different service expectations and perceptions accordingly. We investigate 55,110 customer reviews and ratings of New York City's accommodation providers and indeed find evidence of rating inflation over the eight years studied.
\end{abstract}

Keywords: Customer rating inflation; Customer reviews; Sharing economy; Amateur service providers; automated text analysis 


\section{Introduction}

The growth of the sharing economy has had a significant impact on the nature of the travel industry, both in terms of the expansion of the online travel industry and the number of options available to travelers (Altinay \& Taheri, 2019; Ert et al., 2016; Tussyadiah \& Pesonen, 2016; Zervas et al., 2017). With the increase in options available to consumers, online word-of-mouth (eWOM) is a useful tool to sort through the many choices based on previous consumers' opinions. eWOM is seen by many consumers as unbiased (Hennig-Thurau et al., 2004) and considered to be more trustworthy than information provided by service providers or manufacturers (Dickinger, 2011). eWOM not only contributes to and often changes purchasing behavior (Chen et al., 2011; Filieri, 2016) but can also reduce some of the risk associated with online purchases (Flanagin et al., 2014).

Recently, a trend has been identified where eWOM, in the form of online reviews and ratings, may be influenced by the positioning of the accommodation provider. In a study analyzing customer ratings on the site Booking.com, there was a significantly larger number of higher ratings for hotels that were classified as a 4- or 5-star hotel as opposed to hotels classified below 3 stars (Mariani \& Borghi, 2018). Another study found significant differences between customer ratings of Airbnb accommodations and hotel accommodations listed on TripAdvisor with Airbnb having significantly higher average customer ratings (4.7) compared to TripAdvisor (3.8) (Zervas et al., 2015). This discrepancy in ratings could make eWOM a meaningless tool for consumers in their decision-making process and for managers in diagnosing areas of service weakness.

To understand why there is a difference in online ratings between accommodation types, two different types of accommodation providers are considered in this study, namely "amateur" and "professional". Amateur accommodation providers are associated with the sharing- or peer-to-peer economy whereas professional accommodation providers are associated with traditional services and established businesses. This positioning in the market as an amateur versus a professional likely creates different service quality expectations (Boulding \& Kirmani, 1993; Connelly et al., 2011), more intimate connections (Ert et al., 2016; Tussyadiah \& Pesonen, 2016), feelings of goodwill (Spence \& Rutherfoord, 2003) and reciprocity (Fehr \& Gächter, 2000). Thus, amateur service providers might receive different and preferential treatment when customers rate and review their services compared to those of similar professional service providers.

This paper makes several contributions to the hospitality and marketing literature and managerial practice. First, eWOM literature and the customer perceptions of professional and amateur accommodation providers are discussed. Second, a series of hypotheses are tested using 55,110 customer reviews from the TripAdvisor platform over a period of eight years. Third, the paper prescribes strategies to guide potential customers, managers, and public policy officials on the problems of, and how to deal with, inflated customer ratings. Finally, the paper suggests new research directions that investigate rating inflation in other contexts.

\section{Conceptual Development}

\section{eWOM}

Electronic word-of-mouth, or "eWOM" is "any positive or negative statement made by potential, actual, or former customers about a product or company, which is made available to a multitude of people and institutions via the Internet" (Hennig-Thurau et al., 2004, p. 39). Despite the easy access to eWOM for different products and services, the high volume of customer reviews and ratings available can be overwhelming and impede discerning their credibility (Mudambi et al., 2014). Customer reviews are written appraisals that often provide a detailed description of the customer experience and service 
encounter and usually offer diagnostic information about the service quality experienced. Customer ratings are quantitative indicators that summarize the customer experience (Kim et al., 2017; Ögüt \& Onur Taş, 2012). While the exact details or scale may change depending on the eWOM platform (Mudambi et al., 2014), these ratings are often represented either numerically or graphically in the form of stars or circles that are easily processed by potential customers due to their simple nature (Adomavicius \& Kwon, 2012; Flanagin et al., 2014; Sparks \& Browning, 2011).

On a typical e-commerce platform, customer ratings are presented as an average or aggregated rating and shows the number of customer reviews, including a visual breakdown of the associated ratings by means of a simple bar graph (Flanagin et al., 2014; Mudambi et al., 2014). This information is intended to provide potential customers with a snapshot of how other customers rated their experience with the service or product. However, when customer ratings are accompanied by customers' textual reviews, there can be some discrepancy between a written review and a star rating, which might confuse the potential customer (Mudambi et al., 2014). For example, two customers may have written very similar online reviews as they had similar experiences with a service provider, but when providing a rating one customer might choose a two out of five, and the other a four. There are many factors that explain these customer rating discrepancies including differences in national culture (Laroche et al., 2004; Mattila, 2000), a variety of demographic characteristics (Mattila, 2000; Mittal \& Kamakura, 2001), subjective norm variations (Conlin et al., 2003), or length and depth of customer relationships (Pizam et al., 2000).

eWOM is largely driven by a concern for other customers (Chen et al., 2011; Hennig-Thurau et al., 2004). In hospitality, eWOM is primarily motivated by positive intentions rather than as a way to vent negative feelings (Yen \& Tang, 2015; King et al., 2014). Positive motivations include a desire to help hospitality providers, a concern for others (future customers), or to fulfill needs for enjoyment and selfenhancement.

As mentioned earlier, peer-to-peer accommodation providers are referred to as "amateurs" (from the Latin amo - "I love"), because for most of these providers the provision of accommodation services might be a part-time occupation, or a way of earning extra income. They are likely to be less skilled or less experienced in the domain (Juniu et al., 1996; Krause et al., 2010) and do it for the love of it. In contrast, "professional" accommodation providers do so because it is their full-time business and a primary way of earning a profit. They are likely to possess more experience and skills. The use of "amateur" and "professionals" as "market labels" is to distinguish between the two different types of accommodation providers.

A variety of hospitality-specific social media platforms enable potential customers to research past customers' experiences with specific accommodation providers. TripAdvisor, the largest travel eWOM platform, stands out as the market leader. High ratings on this platform of an accommodation increase both awareness of, and the booking likelihood for, a venue (Sparks \& Browning, 2011). Average customer ratings rely on individual customer ratings to be a diagnostic evaluation of the service experienced, yet overall, there is evidence to suggest that these ratings have increased positively over time with no hard evidence of associated increases in service quality (Mariani \& Borghi, 2018). In order to extend the time period looked at for evidence of an increase in ratings, the following is hypothesized:

$H_{1}$ : Individual customer ratings of both amateur and professional accommodation providers are increasing over time.

\section{Customer Reviews and Automated Text Analysis}

While reducing the information contained in a customer's experience down to a simple number provides a quick and easy summary for others, the words expressed in customer reviews contain rich 
information, which can be more insightful to customers. These customer reviews are well suited for automated text analysis, a computational method that allows researchers to uncover patterns in text that would otherwise be difficult to discover manually (Humphreys \& Wang, 2017). The political scientist Roderick Hart (1984) developed his theory of word choice and verbal tone by asking, "if five fundamental questions could be asked of any piece of text, what would they be?" These questions reveal comprehensive meaning and insight into the extent to which a piece of text (1) is certain, (2) optimistic (or pessimistic), (3) exhibits activity, (4) is realistic, and (5) exhibits commonality. The DICTION 5.0 text analysis software developed by Hart (2000) enables a researcher to gauge these five dimensions within a piece of text.

The first dimension, certainty, involves language and words that indicate resoluteness, inflexibility, completeness, and a tendency to speak with authority (Hart, 1984; 2000). Thus, when customers write very negative reviews of an accommodation, it is likely that these reviews will be adamant and unwavering in their criticism. Similarly, when customers write very positive reviews of an accommodation, it is likely that these reviews will be resolute, purposeful, and unswerving in their praise. Customer reviews that fall in the middle range tend to express less certainty, leading to the following hypothesis:

$\mathrm{H}_{2}$ : Customer reviews that score high on certainty will be associated with the highest and lowest ratings compared to reviews with middle range ratings.

Optimism describes language that endorses an individual, a group, a concept, or an event and also reflects the nature of the writer of the text (Hart, 1984; 2000). Customers writing very positive reviews will most likely use words that endorse the accommodation and express affirmative opinions on the accommodation's location, setting, and employees. In contrast, customers writing highly negative reviews will use words more closely associated with pessimism, be unlikely to endorse anything, and will likely share negative opinions on the various attributes of the accommodation.

Therefore, the following is hypothesized:

$\mathrm{H}_{3}$ : Customer reviews that are more optimistic will be associated with significantly higher customer ratings.

Activity involves language that is about movement, change, and the implementation of ideas and the avoidance of inertia (Hart, 1984; 2000). In hospitality, activity happens in many forms, some of which may be associated with positive or negative experiences. Customer reviews with high activity scores could be associated with high ratings when the language containing activity pertains to positive attributes, such as participating in activities that are close in proximity, or the ability to walk to attractions because of the prime location. Similarly, reviews with language expressing activity may be referring to negative experiences, such as having to move rooms because of comfort, cleanliness, or having to walk a long distance to the nearest public transport station because of poor location. Thus, the following is hypothesized:

$\mathrm{H}_{4}$ : Customer reviews that score high on activity will be associated with the higher or lower ratings compared to those reviews in the middle rating range.

Realism describes the extent to which a piece of text is pragmatic and thus has to do with language that is tangible, immediate, and deals with recognizable issues (Hart, 1984; 2000). Reviews with high realism scores are more likely to be associated with middle range ratings describing the mundane 
aspects of an accommodation. In contrast, extremely low and extremely highly rated reviews will be more likely to be associated with low realism scores as reviewers may embellish the positive or negative aspects of an accommodation. Therefore, the following is hypothesized:

$H_{5}$ : Customer reviews that score high on realism will be associated with middle range ratings compared to reviews that score low on realism.

Commonality details language that communicates communitarian concepts and highlights the agreed-upon values of a group of individuals and rejects language that is idiosyncratic in terms of engagement (Hart 1984; 2000). Reviews containing more communalistic language are often driven by offering social and emotional support and helping others (Munar \& Jacobsen, 2014). It is therefore likely that there will be more commonality in more positive reviews as customers writing reviews seek to provide helpful information that guides future customers to enjoy the same kind of experience the reviewer had. Thus, the following is hypothesized:

$H_{6}$ : Customer reviews with high commonality scores will be associated with higher customer ratings.

\section{Positioning in the Accommodation Industry}

Next, conditions under which the above relationships change depending on how an organization positions or presents itself or is perceived in the marketplace are examined. Amateur and professional providers differ in a number of ways inlcluding by the tangible evidence they exhibit that can indicate their level of professionalism (Shostack, 1977). For example, a professional hotel may have branded stationary at the front desk serviced by employees in uniforms with name badges and standard rooms. A peer-to-peer vacation rental on the other hand may not have branded stationary, will likely not have a front desk or staff in uniforms, and even the rooms will probably not all be identical.

Organizations regarded as "professional" in their market most likely create higher expectations of service quality and performance than those perceived by customers as "amateur". In the accommodation industry, professional service providers are well established and licensed accommodation providers often with multiple locations, whereas amateur service providers are individuals or groups listing their personal or spare space (e.g., a sofa, a spare bedroom, or a second apartment) as accommodation for tourists or visitors through sharing economy platforms such as, Couchsurfing, or Airbnb. There is a range of accommodation service providers between these two extremes. However, for the purpose of this study only the accommodation providers in these two extremes are explored in the empirical work below.

Being regarded by a customer as an amateur or a professional provider might act as a signal of perceived service quality, and this could alter a customer's service expectations before consumption (Spence, 1978; Boulding \& Kirmani, 1993; Connelly et al., 2011). For example, there are likely lower service quality and performance levels expected of amateur providers than those expected of professional providers. Furthermore, amateur service providers might also be more likely to engender goodwill with customers and other stakeholders (Spence \& Rutherfoord, 2003) and customers might be more forgiving of an amateur service provider than a professional. Thus, the following hypothesis is as follows:

$H_{7}$ : A customer's perception of an accommodation provider as an amateur will cause them to award higher ratings than to an accommodation provider perceived as a professional. 
Amateur and professional accommodation providers differ in several aspects, including some of the more obvious characteristics such as staff, décor, knowledge, standardization, consistency and expertise. Customers are more likely to interact with their host at their chosen amateur accommodation than they are to interact with the owner of a hotel chain at a professional accommodation. This type of connection between the customer and host of an amateur accommodation can range from online communication to an in-person interaction. The level of social interaction between an amateur accommodation provider and a customer would be more intimate than between that of a professional accommodation provider and a customer (Ert et al., 2016; Tussyadiah \& Pesonen, 2016). Thus, this relative increased intimacy with amateur service providers compared to professional service providers enhances customer reciprocity (e.g., kindness is rewarded by a kind online review), resulting in more favorable customer reviews for amateur accommodations (Fehr \& Gächter, 2000). Therefore, the following is hypothesized:

$H_{8}$ : An accommodation provider's label as an amateur, changes how customers express themselves in reviews compared to those labeled as a professional.

Customers who leave customer reviews for amateur service providers are likely to use language that confidently expresses their opinions in a way that is clear and understandable (Hart, 2000). This could be because of their more intimate connection with the provider (Ert et al., 2016), feelings of goodwill (Spence \& Rutherfoord, 2003) and desire for reciprocity (Fehr \& Gächter, 2000). These connections and feelings also likely translate into more favorable or optimistic language with amateur providers compared to professionals. Customers may understand the difficulty in competing against professional providers and feel a sense of obligation to vouch for or endorse the host and encourage potential customers to visit and stay at the accommodation. Therefore, the following hypotheses are proposed:

$H_{8 a}$ : Customer reviews of amateur accommodation providers will have higher levels of certainty than for professionals.

$H_{8 b}$ : Customer reviews of amateur accommodation providers will have higher levels of optimism than for professionals.

Customer reviews of amateur accommodation providers are also likely to express movement and change. Staying in an amateur accommodation could fulfill a customer's desire to 'live like the locals' by using the advanced local knowledge of the provider and engage in the same activities that are typical of that locale (Week, 2012). A customer review of an amateur accommodation would probably highlight the unique activities that the traveler was able to engage in due to the host or the location of the accommodation. Therefore, the following is hypothesized:

$H_{8 c}$ : Customer reviews of amateur accommodation providers will have higher levels of activity than for professionals.

As concern for others is a factor that motivates consumers to write an online review (Hennig-Thurau et al., 2004; Yen \& Tang, 2015), customers who write reviews for an amateur accommodation provider may recognize from experience the value and usefulness of honest customer reviews when it comes to the search phase. Therefore, when writing their customer review they will be more likely to include concepts that are relatable and important to other potential consumers to better inform their decisions. Furthermore, customers may use more communal language in their reviews to either dispel or confirm the common hesitations held by potential customers when they are searching for amateur 
accommodations compared to customer reviews for professional providers. Therefore, the following two hypotheses are proposed:

$H_{8 d}$ : Customer reviews of amateur accommodation providers will have higher levels of realism than for professionals.

$H_{8 e}$ : Customer reviews of amateur accommodation providers will have higher levels of commonality than for professionals.

\section{Method}

In this section, the hypotheses developed above are tested using 55,110 customer reviews and ratings over eight years of New York City's accommodation providers. These data were collected from TripAdvisor, which is a global social media platform and contains 700 million customer reviews and ratings for over 8.3 million travel and hospitality service providers (TripAdvisor, 2019). TripAdvisor is the optimal empirical site on which to test these hypotheses as it contains customer reviews and ratings for both professional and amateur (i.e., vacation or holiday rentals) accommodation providers, it is a trusted source of information that customers use to make purchase decisions, and it is also an established platform on which many years of data are available.

The customer reviews and ratings data were collected from the TripAdvisor platform using data scraping software. TripAdvisor platform users document their travel experiences by leaving textual reviews, uploading pictures, and providing a rating on a one (i.e., terrible) to five (i.e., excellent) scale. The data collection was restricted to hotels and vacation rentals in New York City under US\$250 per night for a two-person room for a stay between the $18^{\text {th }}$ to the $24^{\text {th }}$ of October 2017. New York City was chosen as it is consistently ranked in the top 10 most visited cities by international tourists (MasterCard, n.d.). An English-speaking destination was also important to increase the likelihood of reviews written in English. New York City is the most visited city in the US by domestic tourists further increasing the likelihood of reviews written in English (NYC \& Company, 2017). The time period was selected so as to avoid any high season prices associated with high tourist numbers.

The amateur accommodation provider (i.e., vacation rentals on the TripAdvisor platform) customer reviews and ratings were collected based on the above criteria, which resulted in 708 data records from 116 providers. The before-mentioned criteria were also applied to collect customer reviews and ratings of professional accommodation providers (i.e., hotels on the TripAdvisor platform), which resulted in 54,403 data records from 116 providers. These professional providers were selected as the first hotels presented using the above criteria and the "best value" search result filter.

As a vast amount of textual data was collected from TripAdvisor, an advanced approach to automatically analyze the textual content of the reviews that allows for the processing of textual data into quantitative measures was applied. As discussed in the conceptual development section, the DICTON 5.0 software based on Hart (2000)'s theory of word choice and verbal tone was used. This software has been used in previous studies analyzing online text data from online reviews on the employer rating website, Glassdoor, to messages on the social networking site, Facebook (De Moya \& Jain, 2013; Pitt et al., 2017; 2018). The software automatically analyzes the textual content of the review by matching text with 31 pre-constructed dictionaries for the five dimensions referred to above and scoring the review accordingly. To aid interpretation of these customer review content variables, each variable was standardized.

Excluding the five customer review content variables, the dataset also consisted of raw customer ratings ranging from 1 (poor) to 5 (excellent) with an overall mean of 4.15. Customer rating and review data were coded into an "amateur" dummy variable with 1 for amateur providers and o for professional 
providers. Variables were created to evaluate the effect of time in both publication year of the customer eWOM and season in which it was published on the site.

\section{Results}

In this section, variable correlations, a trend analysis over time, group comparisons, regression results, and the testing of hypotheses is presented. There were no high correlations between any two variables (see Table 1). Ratings were significantly positively associated with amateur accommodation providers and year, indicating some initial support for hypothesis 7 and hypothesis 1 respectively. Curiously, optimism and commonality were significantly negatively associated with customer ratings. Year and season are either not significantly correlated or have a fairly low value of significant correlation with the customer review content variables.

Table 2 reports the customer ratings and reviews trends over the years studied. Customer ratings move from a low mean in 2010 of 3.83 to a high in 2017 of $4.22(F(7,55103)=46.101, p<0.001)$ indicating strong support for the notion of customer rating inflation and hypothesis 1 in the eight years and context studied. As Figure 1 indicates, customer reviews have increasingly used more realistic (i.e., tangible and related), active (i.e., moving or planning), and certain (i.e., more direct) language over time. This is in contrast to communalistic (i.e., shared values or similarities) and optimistic (i.e., positive or endorsing) language of customer reviews that have largely remained constant over the eight years studied. Furthermore, in terms of seasonality, the customer rating mean decreases from a high of 4.23 in the first quarter to 4.09 in the fourth quarter $(F(3,55107)=35.278, p<0.001)$.

Regarding the impact of whether the accommodation was amateur or professional on customer ratings and reviews, Table 3 presents significant t-test comparison results in all variables except commonality. Customer ratings were significantly higher for amateur accommodation providers in the dataset with a medium effect size $(t(55109)=-8.589, p<0.001, d=0.325)$. Figure 2 illustrates how this difference changes over time, and while customer rating means for amateur providers are consistently greater over the years studied, it seems that the difference is becoming arithmetically smaller. In terms of the review content dimensions, activity $(t(55109)=-9.013, p<0.001, d=0.341)$, optimism $(t(55109)=-3.846, p<0.001, d=0.220)$, certainty $(t(55109)=-2.835, p<0.001, d=$ $0.107)$, and realism $(t$ (55109) $=-15.435, p<0.001, d=0.584)$ are significantly higher for amateur accommodation providers than for professional providers, supporting hypotheses $8 \mathrm{a}, 8 \mathrm{~b}, 8 \mathrm{c}$, and $8 \mathrm{~d}$ respectively. The exception is commonality that showed no significant difference between the two market labels $(t(55109)=-1.613, p=0.107)$ not supporting hypothesis $8 \mathrm{e}$.

Table 4 reports six customer ratings regression models that explain how variations in customer rating, rated from 1 to 5 , are due to an amateur market label, the customer review content, and the year and season that the customer rating was published. Customer ratings of amateur accommodation providers were consistently significantly higher, between 0.239 to 0.347 of a point, compared to professional accommodation providers, supporting hypothesis 7 .

Turning now to customer review content, all customer content variables were significant predictors of customer ratings (see Table 4). Certain language in customer reviews was significantly associated with higher and lower customer ratings, supporting hypothesis 2. More optimistic language in customer reviews was significantly associated with higher customer ratings, supporting hypothesis 3 . Increased active language was associated with significantly higher customer ratings, but the "u-shaped" relationship postulated in hypothesis 4 was not supported. Higher levels of realistic language were significantly associated with higher customer ratings, but the hypothesized "inverted u-shaped" relationship was only significant in Model 6, thus only partially supporting hypothesis 5 . Communalistic 
language in customer reviews was significantly associated with higher customer rating, thus supporting hypothesis 6.

The year variables show a consistent significant customer rating inflation trend that occurs during the eight years studied, showing further support for hypothesis 1. Furthermore, customer ratings are significantly impacted by the season in which they are published with quarter one having the highest customer ratings and each quarter after that showing a significant decrease that exacerbates as the year progresses. 
Table 1: Variable Correlations

\begin{tabular}{|c|c|c|c|c|c|c|c|c|}
\hline Variable & Rating & Amateur & Activity & Optimism & Certainty & Realism & Commonality & Year \\
\hline Amateur & $0.037^{* \star}$ & & & & & & & \\
\hline Activity & $0.118^{* *}$ & $0.038^{* *}$ & & & & & & \\
\hline Optimism & $-0.097^{* *}$ & $0.016^{* *}$ & $-0.259^{* *}$ & & & & & \\
\hline Certainty & $0.346^{* *}$ & $0.012^{* *}$ & $0.319^{* *}$ & $-0.407^{* *}$ & & & & \\
\hline Realism & $0.111^{* *}$ & $0.066^{* *}$ & $0.058^{* *}$ & $-0.131^{* *}$ & $0.177^{* *}$ & & & \\
\hline Commonality & $-0.023^{\star *}$ & 0.007 & $-0.380^{* *}$ & $0.118^{* *}$ & $-0.168^{* *}$ & $-0.043^{* *}$ & & \\
\hline Year & $0.069^{* *}$ & -0.002 & $0.039^{* *}$ & -0.003 & $0.055^{* *}$ & $0.052^{* *}$ & 0.002 & \\
\hline Season & $-0.039^{* *}$ & $0.010^{*}$ & -0.002 & 0.007 & $-0.020^{* *}$ & 0.002 & 0.001 & $0.160^{*}$ \\
\hline
\end{tabular}

Table 2: Customer Rating and Review Trends Over Time

\begin{tabular}{|lrrrrrrrrr|}
\hline Variable & 2010 & 2011 & 2012 & 2013 & 2014 & 2015 & 2016 & 2017 & ANOVA Sig. \\
\hline Rating & 3.83 & 4.01 & 4.07 & 4.07 & 4.14 & 4.17 & 4.19 & 4.22 & $p<0.001$ \\
Activity* $^{*}-0.096$ & -0.045 & -0.066 & -0.060 & 0.004 & -0.011 & 0.035 & 0.046 & $p<0.001$ \\
Optimism* $^{*}$ & -0.003 & 0.010 & -0.001 & 0.022 & -0.010 & 0.002 & -0.006 & -0.001 & $p=0.732$ \\
Certainty* $^{*}-0.176$ & -0.112 & -0.072 & -0.068 & -0.010 & 0.020 & 0.045 & 0.049 & $p<0.001$ \\
Realism* $^{*}$ & -0.131 & -0.124 & -0.082 & -0.058 & 0.021 & 0.000 & 0.029 & 0.060 & $p<0.001$ \\
Commonality* & 0.011 & -0.031 & -0.016 & 0.023 & 0.019 & -0.016 & -0.004 & 0.006 & $p=0.080$ \\
\hline * Standardized to aid interpretation & & & & & & & \\
\hline
\end{tabular}

Table 3: Customer Rating and Review Content by Market Label

\begin{tabular}{|lcccc|}
\hline Variable & Professional Mean & Amateur Mean & T-Test Sig. & Cohen's $d$ \\
\hline Rating & 4.140 & 4.480 & $p<0.001$ & 0.325 \\
Activity* & -0.004 & 0.336 & $p<0.001$ & 0.341 \\
Optimism* $^{*}$ & -0.002 & 0.144 & $p<0.001$ & 0.220 \\
Certainty* $^{*}$ & -0.001 & 0.106 & $p=0.005$ & 0.107 \\
Realism* & -0.007 & 0.575 & $p<0.001$ & 0.584 \\
Commonality* $^{*}$ & -0.001 & 0.060 & $p=0.107$ & - \\
\hline *Variable was standardized to aid interpretation & & \\
\hline
\end{tabular}


Table 4: Customer Ratings Regression Models Results*

\begin{tabular}{|c|c|c|c|c|c|c|}
\hline Model & 1 & 2 & 3 & 4 & 5 & 6 \\
\hline Amateur & 0.339 & & 0.347 & & & 0.239 \\
\hline Activity & & & & 0.051 & 0.050 & 0.049 \\
\hline$-(\text { Activity })^{2}$ & & & & $0.001^{\mathrm{a}}$ & $0.001^{\mathrm{a}}$ & $0.001^{\mathrm{a}}$ \\
\hline Optimism & & & & 0.023 & 0.021 & 0.021 \\
\hline Certainty & & & & 0.385 & 0.382 & 0.382 \\
\hline$-(\text { Certainty })^{2}$ & & & & 0.100 & 0.100 & 0.100 \\
\hline Realism & & & & 0.058 & 0.056 & 0.054 \\
\hline$(\text { Realism })^{2}$ & & & & $-0.005^{a}$ & $-0.005^{\mathrm{a}}$ & $-0.005^{b}$ \\
\hline Commonality & & & & 0.032 & 0.031 & 0.030 \\
\hline 2011 & & 0.186 & 0.185 & & 0.149 & 0.149 \\
\hline 2012 & & 0.235 & 0.232 & & 0.178 & 0.175 \\
\hline 2013 & & 0.231 & 0.229 & & 0.156 & 0.155 \\
\hline 2014 & & 0.306 & 0.304 & & 0.209 & 0.208 \\
\hline 2015 & & 0.339 & 0.338 & & 0.234 & 0.234 \\
\hline 2016 & & 0.357 & 0.356 & & 0.240 & 0.240 \\
\hline 2017 & & 0.369 & 0.367 & & 0.261 & 0.260 \\
\hline Quarter 2 & & -0.092 & -0.094 & & -0.079 & -0.080 \\
\hline Quarter 3 & & -0.079 & -0.080 & & -0.069 & -0.070 \\
\hline Quarter 4 & & -0.109 & -0.111 & & -0.093 & -0.094 \\
\hline Constant & 4.142 & 3.909 & 3.907 & 4.253 & 4.099 & 4.098 \\
\hline $\mathrm{R}^{2}$ & 0.001 & 0.007 & 0.008 & 0.154 & 0.158 & 0.159 \\
\hline F Statistic Sig. & $p<0.001$ & $p<0.001$ & $p<0.001$ & $p<0.001$ & $p<0.001$ & $p<0.001$ \\
\hline
\end{tabular}


Figure 1: Customer Reviews' Content Over Time



Figure 2: Customer Rating Trend Over Time by Market Labels

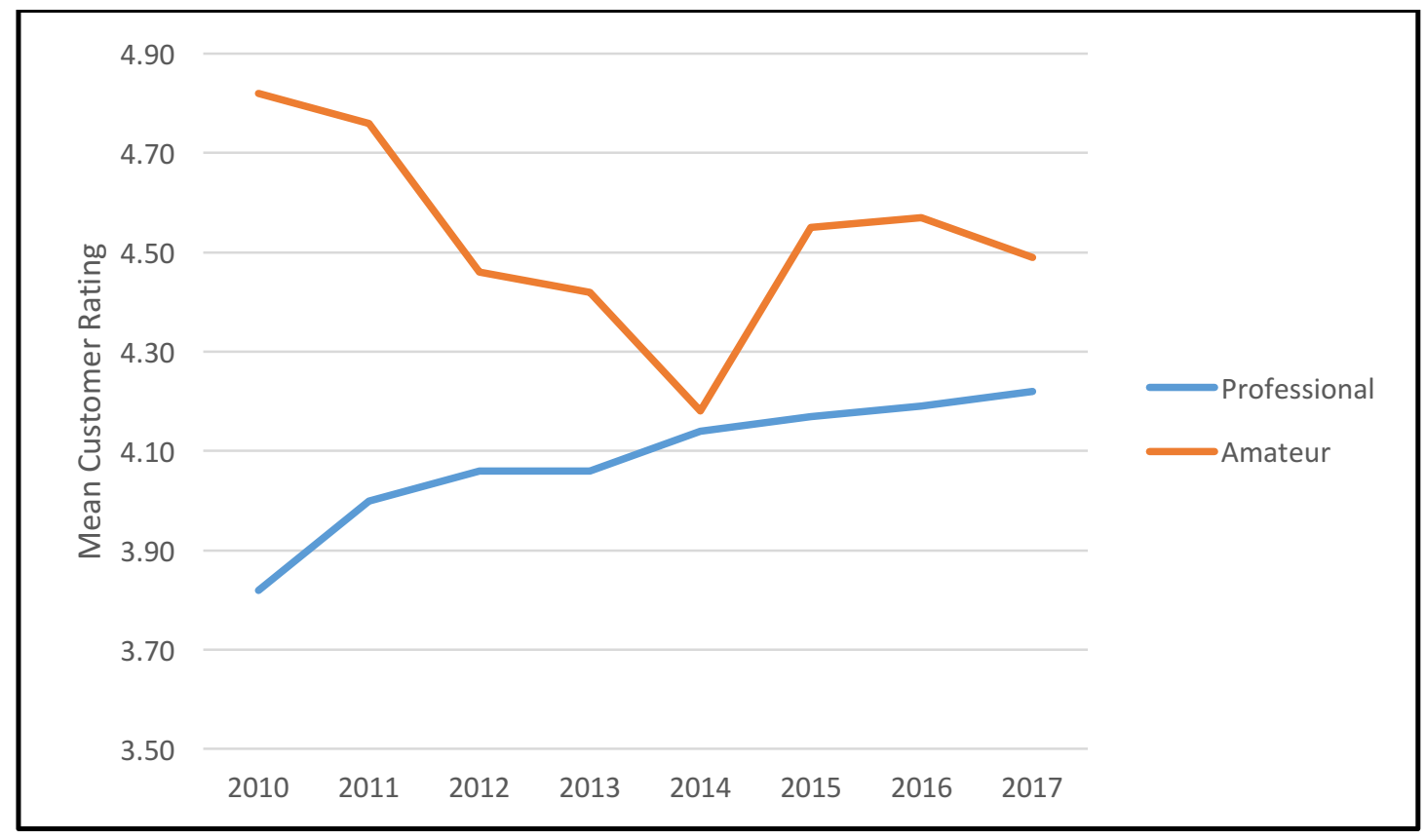




\section{Discussion and Implications}

The study finds that whether customers perceive service providers as either amateurs or professionals significantly impacts their ratings, and the word choice and verbal tone in their reviews. Specifically, providers regarded as amateurs elicit more flattering customer reviews and higher customer ratings compared to those of professional providers. Recent research has indicated the increasing importance of textual data in the form of online customer reviews to managers and researchers (Ert et al., 2016; Pitt et al., 2017). While some evidence exists that there is a difference in terms of customer ratings between traditional hotels and sharing economy service providers (Zervas et al., 2015; 2017), the results presented here confirm this difference and go further by detailing how the customer review content impacts this rating decision. The next section examines the empirical evidence of concerning the hypotheses, linking it back to the existing literature and discusses potential implications for researchers.

The results of the study suggest that customer ratings of accommodation providers are increasing over time in both the traditional and sharing economies. This inflation threatens the value of ratings to prospective customers: When every provider in a category scores 4.5 or above, the information is of little worth to a customer seeking to make a decision. In simple terms, when a potential customer searching for accommodation notices they all have high ratings, the information does not help to differentiate between them and guide the customer's choice. From one year to the next the impact of this may not be substantial, however over several years, as studied above, this trend may present significant issues. Customer rating inflation may change how potential customers use ratings because of changes in value, trustworthiness, and credibility (Flanagin et al., 2014; Mudambi et al., 2014; Sparks \& Browning, 2011). Thus, future research needs to examine consumer scenarios in which customer ratings convey very little real information in order to examine how this impacts potential customer attitudes, intentions, and purchase decisions. For example, when a customer is confronted with a high mean rating for an establishment - say 4.7, and most of the other providers score thereabouts, what heuristics do customers use to make their decisions? Do they perhaps then only consider individual reviews with low ratings, and use those to inform themselves? Or do they rely on simple data such as proximity to attractions and public transport, and simply assume that all accommodation in the area is more or less similar?

Further findings suggest customer reviews associated with different customer ratings contain significantly different content in terms of word choice and verbal tone (Hart, 2000). The highest and the lowest ratings express stronger certainty of the opinion than do the reviews associated with the average ratings. This same relationship was theorized for review content relating to activity. However, it was not supported and the relationship seems to be positive and linear between activity-related content and customer ratings. Rather than using active language in both very negative and very positive reviews, customers are only using active language in highly positive reviews. This could be because of the connection between attractions and the movement associated with exploring a new location when travelling. Similarly, the expected positive and linear relationship with optimistic review content and customer ratings can be seen. Realistic content in customer reviews was hypothesized as being higher at mid-range customer ratings, however this significant non-linear inverted-U relationship was only found when the impact of market labels (amateur versus professionals) was controlled for (see Table 4, Model 4,5 , and 6 ). This may be due to customers wanting to lend more credibility to their positive reviews by using more realistic and down to earth language to increase its value for both future customers and accommodation providers. Finally, as expected, communalistic content was positively associated with ratings of both professional and amateur accommodations. Thus, consumer and marketing researchers, especially those exploring eWOM and its effects on purchasing planning and information gathering, should consider the distribution of customer ratings and their associated reviews rather than only 
focusing on the mean customer rating and associated reviews to understand how different types of customer review content impact consumer behavior.

The findings also show evidence that whether an accommodation provider's status is amateur or professional impacts both customer ratings and reviews. Customer ratings for amateur versus professional accommodation providers were significantly higher over the eight years studied. Customer reviews of amateur accommodations demonstrate higher levels of certainty, optimism, activity, and realism than for professional providers, which may at least partially explain the higher customer ratings for amateur providers. This finding may be due to higher levels of social interaction and intimacy between the amateur providers and customers. Social interaction has been associated with customers' perceptions of authenticity (Week, 2012) and similarity (Cialdini \& Goldstein, 2002; Jiang et al., 2009) and leads to feelings of goodwill towards the service provider and forgiveness of less than optimal service quality (Ert et al., 2016; Tussyadiah \& Pesonen, 2016; Fehr \& Gächter, 2000). Furthermore, compared to professional providers, amateur providers may elicit more customer awareness of the rating consequences (Harris, 1994; Murphy \& Cleveland, 1995) for the provider. For example, poor ratings of an accommodation provider might cause that provider to lose, or go out of, business. Therefore, future research should consider whether service providers are amateur or professional when studying service economies, especially those studies that compare the traditional and sharing economies contexts, as these labels have measurable effects on eWOM. Future researchers could also examine the extent to which the provider-customer intimacy experienced with an amateur provider does indeed drive more favorable customer ratings and reviews. Surprisingly, low communalistic language was evident in ratings of amateur accommodation providers. This could be attributed to the lack of social service scape associated with hotels, which usually consist of other guests and employees, and can have a positive impact on the guest's experience (Line \& Hanks, 2019).

\section{Practical Implications}

The findings have several practical implications for accommodation managers, and platform designers. Although some accommodation managers might rejoice at increased valence of customer ratings, as shown above ratings are increasing at an aggregate level over the eight years studied; thus, managers may not have an accurate sense of what attributed to the increase (e.g., staff training, new staff, renovations, new amenities). When all players achieve high average ratings, it becomes more difficult to differentiate on these scores alone. Instead of relying on customer ratings only, managers should look to other sources of customer experience information to receive feedback on service quality. This is where the use of the text itself, can be more insightful, and perhaps provide greater strategic direction.

Taking negative comments into account is indeed important, however this provides a single source of one customer's experience and may be biased by a number of factors. An analysis of customer reviews' content would offer diagnostic feedback on customers' needs and desires, yet managers are often illequipped to analyze these on aggregate. Understanding these reviews can also help inform managers response strategies to negative reviews and impact overall consensus between eWOM reviews (Lee \& Cranage, 2014). By learning to analyze customer reviews and assess trends using advanced automated text analysis tools, managers can prioritize service quality investments and any corrective action in cases that identify opportunities for service quality improvements.

Even with advanced understanding of customer experiences with the service, the accommodation industry is extremely competitive and as such, managers need to be cognizant of their customer ratings and reviews relative to other similar service providers. To elicit the best customer ratings and reviews, managers can train staff who interact frequently with customers to quickly establish an intimate, social yet professional relationship that evokes feelings of goodwill towards the provider. Establishing this 
kind of relationship early in the service encounter is needed even more with professional providers that are now not only competing with other professional providers but also amateurs who were hypothesized to bring out feelings of goodwill more or less automatically. Professional providers may want to implement strategies for staff to interact with guests in a more informal and personal way that lowers barriers between staff and customers. Managers can track the effectiveness of this training by analyzing customer reviews for optimism, certainty, and commonality, outside of simply tracking customer ratings.

Designers and managers of accommodation and other service platforms have to be wary of customer rating inflation and the associated effects on customer ratings in order to ensure that customers keep on using their platforms. There is a risk that inflated customer ratings could render these ratings of little value to potential customers, as they no longer provide diagnostic information on the service experience.

\section{Conclusions}

\section{Limitations and Future Research}

As with any research, this study has some limitations. First, TripAdvisor does not require confirmation from a reviewer that they have used the services they choose to review, which means that review data may be corrupted by a small number of users who skew the aggregate reported scores. However, eWOM literature (Racherla et al., 2013) suggests that these incidents are rare and that the reported aggregate scores are still functionally valid. Furthermore, a very large sample of customer eWOM was collected over a large sample of accommodation providers, thus any distortion from deceptive reviews would be marginal at worst. Further research could examine social media platforms where purchase is taken through the platform, such as Hotels.com or OpenTable for example.

While the decision was made to collect the same number of amateur and professional accommodation providers using the same social media platform, the ultimate number of reviews and ratings in these groups is very different. Two attempts have been made to overcome this difference: by collecting a relatively large sample of customer eWOM on amateur providers and by reporting the Cohen's $d$ which is a statistical measure of effect size that corrects for differences in the size of data groups (Cohen, 1992). Future research could seek a different social media platform that has both types of providers and then test similar numbers of customer eWOM samples from both professionals and amateurs.

Furthermore, this research addresses one distinct geographic and cultural location in North America and does not review possible cultural or language differences as only English customer reviews were processed. Thus, future research could examine eWOM from other sources that are broader in scope in terms of geography, culture, language, and other service attributes.

This paper explores how customer experiences are translated into customer ratings and reviews and makes several contributions to the travel, eWOM, marketing, and management literature. After reviewing the literature on customer rating biases and the concept of market labels and explore their implications, the implications of how accommodation providers in both the traditional and sharing economy contexts are perceived as professional or amateur respectively were examined. After developing a series of hypotheses, they were tested using a large dataset of eWOM regarding accommodation providers over eight years finding evidence of customer rating inflation both over time and with amateur providers and how this is reflected in customer reviews. Based on the findings, implications for future researchers were reported, especially in the sharing economy, that highlight the potential biases of rating inflation and market labels. Practical implications are provided for managers 
to use eWOM data to remain competitive by using helpful feedback from customers and establishing a closer, more intimate relationship with customers.

Online customer reviews and ratings continue to influence potential customers purchase decisions and are increasing in importance as customers adopt new alternatives to hotels and other traditional accommodation providers. Customers may feel more empowered with this additional information about the service providers they are considering, however they may be unaware of potential biases in eWOM. Customer rating inflation and changes in customer reviews' content in the sharing economy presents a threat to potential customers as well as accommodation providers as this eWOM may no longer be diagnostic and reliable sources of information. 


\section{Sources}

Adomavicius, G., \& Kwon, Y. (2012). Improving aggregate recommendation diversity using ranking-based techniques. IEEE Transactions on Knowledge and Data Engineering, 24(5), 896-911.

Altinay, L., \& Taheri, B. (2019). Emerging themes and theories in the sharing economy: a critical note for hospitality and tourism. International Journal of Contemporary Hospitality Management, 31(1), 180-193.

Boulding, W., \& Kirmani, A. (1993). A consumer-side experimental examination of signaling theory: do consumers perceive warranties as signals of quality?. Journal of Consumer Research, 20(1), 111-123.

Chen, Y., Fay, S., \& Wang, Q. (2011). The role of marketing in social media: How online consumer reviews evolve. Journal of Interactive Marketing, 25(2), 85-94.

Cialdini, R. B., \& Goldstein, N. J. (2002). The science and practice of persuasion. Cornell Hotel and Restaurant Administration Quarterly, 43(2), 40-50.

Cohen, J. (1992). A power primer. Psychological Bulletin, 112(1), 155.

Conlin, M., Lynn, M., \& O'Donoghue, T. (2003). The norm of restaurant tipping. Journal of Economic Behavior \& Organization, 52(3), 297-321.

Connelly, B. L., Certo, S. T., Ireland, R. D., \& Reutzel, C. R. (2011). Signaling theory: A review and assessment. Journal of Management, 37(1), 39-67.

De Moya, M. and Jain, R. (2013). When tourists are your "friends": Exploring the brand personality of Mexico and Brazil on

Facebook. Public Relations Review, 39(1), 23-29.

Dickinger, A. (2011). The trustworthiness of online channels for experience-and goal-directed search tasks. Journal of Travel Research, 50(4), 378-391.

Ert, E., Fleischer, A., \& Magen, N. (2016). Trust and reputation in the sharing economy: The role of personal photos in

Airbnb. Tourism Management, 55, 62-73.

Fehr, E., \& Gächter, S. (2000). Fairness and retaliation: The economics of reciprocity. Journal of Economic

Perspectives, 14(3), 159-181.

Filieri, R. (2016). What makes an online consumer review trustworthy? Annals of Tourism Research, 58, 46-64.

Flanagin, A., Metzger, M., Pure, R., Markov, A. and Hartsell, E. (2014). Mitigating risk in

ecommerce transactions: perceptions of information credibility and the role of user-generated ratings in product quality and purchase intention. Electronic Commerce Research, 14(1), 1-23.

Harris, M. M. (1994). Rater motivation in the performance appraisal context: A theoretical framework. Journal of

Management, 20(4), 735-756.

Hart, R. P. (1984). Systematic analysis of political discourse: The development of DICTION. Political Communication

Yearbook, 1, 97-134.

Hart, R. (2000). Diction 5.0, the text-analysis program user's manual, Scolari Software.

Hennig-Thurau, T., Gwinner, K. P., Walsh, G., \& Gremler, D. D. (2004). Electronic word-of-mouth via consumer-opinion

platforms: what motivates consumers to articulate themselves on the internet? Journal of Interactive Marketing, 18(1), 38-52.

Humphreys, A., \& Wang, R. J. H. (2017). Automated text analysis for consumer research. Journal of Consumer

Research, 44(6), 1274-1306.

Jiang, L., Hoegg, J., Dahl, D. W., \& Chattopadhyay, A. (2009). The persuasive role of incidental similarity on attitudes and purchase intentions in a sales context. Journal of Consumer Research, 36(5), 778-791.

Juniu, S., Tedrick, T., \& Boyd, R. (1996). Leisure or work?: Amateur and professional musicians' perception of rehearsal and performance. Journal of Leisure Research, 28(1), 44-56.

Kim, W. G., \& Park, S. A. (2017). Social media review rating versus traditional customer satisfaction: Which one has more incremental predictive power in explaining hotel performance?. International Journal of Contemporary Hospitality

Management, 29(2), 784-802.

King, R. A., Racherla, P., \& Bush, V. D. (2014). What we know and don't know about online word-of-mouth: A review and synthesis of the literature. Journal of Interactive Marketing, 28(3), 167-183.

Krause, V., Pollok, B., \& Schnitzler, A. (2010). Perception in action: the impact of sensory information on sensorimotor synchronization in musicians and non-musicians. Acta Psychologica, 133(1), 28-37.

Laroche, M., Ueltschy, L. C., Abe, S., Cleveland, M., \& Yannopoulos, P. P. (2004). Service quality perceptions and customer satisfaction: evaluating the role of culture. Journal of International Marketing, 12(3), 58-85.

Lee, C. H., \& Cranage, D. A. (2014). Toward understanding consumer processing of negative online word-of-mouth communication: the roles of opinion consensus and organizational response strategies. Journal of Hospitality \& Tourism Research, 38(3), 330-360.

Line, N. D. and Hanks, L. (2019). The social servicescape: understanding the effects in the full-service hotel industry. International Journal of Contemporary Hospitality Management, 31(2), 753-770.

Mariani, M. M., \& Borghi, M. (2018). Effects of the Booking.com rating system: Bringing hotel class into the picture. Tourism Management, 66, 47-52.

MasterCard. n.d. Number of international overnight visitors in the most popular city destinations worldwide in 2017 (in millions), Statista, available at: https://www-statista-com.proxy.lib.sfu.ca/statistics/310355/overnight-visitors-to-top-citydestinations-worldwide/. 
Mattila, A. S. (2000). The impact of culture and gender on customer evaluations of service encounters. Journal of Hospitality \& Tourism Research, 24(2), 263-273.

Mittal, V. and Kamakura, W. (2001). Satisfaction, repurchase intent, and repurchase behavior: Investigating the moderating effect of customer characteristics. Journal of Marketing Research, 38(1), 131-142.

Mudambi, S. M., Schuff, D., \& Zhang, Z. (2014). Why aren't the stars aligned? An analysis of online review content and star ratings. Proceedings of the 2014 47th Hawaii International Conference on System Sciences, Waikoloa, HI.

Murphy, K. R., \& Cleveland, J. N. (1995). Understanding performance appraisal: Social, organizational, and goal-based perspectives. Sage.

Munar, A. M., \& Jacobsen, J. K. S. (2014). Motivations for sharing tourism experiences through social media. Tourism Management, 43, 46-54.

NYC \& Company (2017). "New York City travel and tourism trend report", available at:

https://www.nycgo.com/assets/files/pdf/new_york_city travel_and tourism_trend_report 2017.pdf (accessed 14 January 2019).

Öğüt, H., \& Onur Taş, B. K. (2012). The influence of internet customer reviews on the online sales and prices in hotel industry. The Service Industries Journal, 32(2), 197-214.

Pitt, C. S., Botha, E., Ferreira, J. J. and Kietzmann, J. (2018). Employee brand engagement on social media: Managing optimism and commonality. Business Horizons, 61(4), 635-642.

Pitt, C. S., Plangger, K. A., Botha, E., Kietzmann, J., \& Pitt, L. (2017). How employees engage with B2B brands on social media: Word choice and verbal tone. Industrial Marketing Management. In press.

Pizam, A., Uriely, N., \& Reichel, A. (2000). The intensity of tourist-host social relationship and its effects on satisfaction and change of attitudes: The case of working tourists in Israel. Tourism Management, 21(4), 395-406.

Racherla, P., Connolly, D. J., \& Christodoulidou, N. (2013). What determines consumers' ratings of service providers? An exploratory study of online traveler reviews. Journal of Hospitality Marketing \& Management, 22(2), 135-161.

Shostack, G. L. (1977). Breaking free from product marketing. Journal of marketing, 41(2), 73-80.

Sparks, B. A., \& Browning, V. (2011). The impact of online reviews on hotel booking intentions and perception of trust. Tourism Management, 32(6), 1310-1323.

Spence, L. J., \& Rutherfoord, R. (2003). Small business and empirical perspectives in business ethics. Journal of Business Ethics, 47(1), 1-5.

Spence, M. (1978). Job market signaling. The Quarterly Journal of Economics, 87(3), 355-374.

TripAdvisor (2019). About us. Retrieved from https://tripadvisor.mediaroom.com/caen-about-us

Tussyadiah, I. P., \& Pesonen, J. (2016). Impacts of peer-to-peer accommodation use on travel patterns. Journal of Travel

Research, 55(8), 1022-1040.

Week, L. (2012). I am not a tourist: Aims and implications of "traveling". Tourist Studies, 12(2), 186-203.

Yen, C. L. A., \& Tang, C. H. H. (2015). Hotel attribute performance, eWOM motivations, and media choice. International Journal of Hospitality Management, 46, 79-88.

Zervas, G., Proserpio, D., \& Byers, J. W. (2017). The rise of the sharing economy: Estimating the impact of Airbnb on the hotel industry. Journal of Marketing Research, 54(5), 687-705.

Zervas, G., Proserpio, D., \& Byers, J. (2015). A first look at online reputation on Airbnb, where every stay is above average. SSRN: http://ssrn.com/abstract=2554500 